\title{
Multiobjective Service Restoration Considering Primary Customers using Hybrid GA-ACO Algorithm
}

\author{
Rajneesh K.Karn \\ Research Scholar \\ MANIT, Bhopal
}

\author{
Yogendra Kumar \\ Professor, Electrical Engg. \\ MANIT, Bhopal
}

\author{
Gayatri Agnihotri \\ Professor, Electrical Engg. \\ MANIT, Bhopal
}

\begin{abstract}
To restore electricity service in healthy area outside the faulted zone in power distribution system is known as service restoration. In this paper, a technique based on hybrid Genetic Algorithm-Ant Colony Optimization (GA-ACO) is presented for solving the service restoration problem in electric power distribution system. Due the presence of various conflicting objectives and constraints, the task of service restoration is multi-objective and multi-constraint optimization problem. In contrast to conventional optimization technique, this approach does not require tunable weighting factors to convert multiple objectives into equivalent single objective. In this work various practical distribution systems issues such as presence of priority customers, remotely and manually controlled switches etc have been considered as objective functions. Based on simulation results on four different distribution networks, the performance of hybrid GA-ACO is found significantly better than Non Dominated Sorting of Genetic Algorithm-II (NSGA-II) and conventional Genetic Algorithm.
\end{abstract}

Keywords: Electric power distribution systems, Priority customers, Ranking based Ant colony optimization, Service restoration

\section{INTRODUCTION}

Due to huge expansion of electric power system the distribution systems have been more complex and hence faulted events are unavoidable. These faults affect the system's reliability and customer's satisfaction. When a fault occurs, in order to ensure minimal reduction in system reliability, the healthy areas isolated by the fault should be supplied with power. This procedure is called service restoration. The main objective of service restoration is to restore as many loads as possible by transferring loads in the out of service areas to other distribution feeders via changing the status of normally closed and normally open switches which is known as network reconfiguration. .

After occurrence of the fault, the operator finds the location of fault, isolate the fault and then restore the service to the healthy components of the out of service area. To meet the service restoration, the alteration of topological structure of distribution system is done by changing the status of switches in distribution system satisfying electrical and structural constraints. However, in process of service restorations, several related issues must also be considered as follows.

(i) Restore as much load as possible within the out of service area.

(ii) The required number of switching operations in the restoration plan should be minimal. Now, in the early days, only manually controlled switches (MCS) were used in a distribution system. Recently, these MCS have been started to be replaced by remote, automatic control switches (ACS). As MCS have not been completely replaced by ACS in most part of the world, both these types of switches exist in almost all the developing power distribution systems in the world. However, the operating times of MCS and ACS are different. Therefore, both these types of switches should be considered in the service restoration study.

(iii) The configuration of the restored system should be as close to the original configuration as possible.

(iv) Radial system structure must be retained.

(v) To maintain the safety and security of different power system components (such as transformer and lines etc.), it is important that the bus voltage and line current should not cross their respective operational limits.

(vi) The restoration plan must be reached in very short time. Hence, the software run time required by the service restoration algorithm should be minimized for speedier solution.

(vii) From economic point of view, there should be minimum power loss in the system after the service restoration is accomplished.

(viii)In any distribution system, there are always some loads, which are of highest priority (e.g. hospital). In the event of partial service restoration, the supply must be restored to highest priority customers and this fact should be reflected in the final solution of service restoration problem.

For the modern day distribution system, it is hard to implement service restoration solely depending on experimental rules by human operators. To reduce the out of service area as efficiently as possible and the burden of operators, a computer aided decision supports assist the operators. The researchers have developed many methods to solve the service restoration problem in distribution systems [1]-[21]. Heuristic techniques [1]-[4] and Expert systems [5][8] have been developed to quickly determine restoration plans and build look-up tables for distribution personals, but both of the above approaches require knowledge base of switching sequence used by the operators for service restoration. This knowledge base is stored in form of rules which are used by the above two approaches to get appropriate solution. However, the required knowledge base of switching sequence of the operators is a complex task to collect. In Fuzzy set approaches [9]-[10], out of service load, number of switching operation, line current, load voltage etc are taken as fuzzy variables and the solution is found on the basis of maximum membership function. But it also does not guarantee optimal solution. Conventional GA based techniques [11]-[17] have also been proposed for service restoration in which multi objective optimization problem is converted into a single objective optimization by using weighting factors and subsequently, GA is used to solve this single objective function. Now the values of weighting factors depends upon the importance of objective functions as well as on the scaling of the objective functions and constraints. As the values of the objective functions and constraints vary from 
network to network, scaling factors also vary from network to network which in turn causes the variation of weighting factors for different networks. Hence for every network, weighting factors should be tuned accordingly. The improved technique using GA is Advanced NSGA-II developed by Deb et al [34] and applied by Y.Kumar et al [18] where for solving the service restoration problem, the multi objective nature of the problem is retained without the need for any tunable weights or parameters. As, a result, the proposed algorithm is generalized enough to be applicable to any power distribution network. But due to radial operation of distribution network, GA based on binary code generates a lot of infeasible solution in the evolutionary process and memory space required is very high. Among all above techniques a new metaheuristic approach 'Ant Colony Optimization' [26]-[30] influenced by the behavior of real ants was proposed by Dorigo, Maniezzo and Colorni in 1992. In early stage this approach was implemented for Travelling Salesman Problem [26]. After the successful implementation of ACO, this new kind of Metahuristic technique based on swarm intelligence was proposed for various combinatorial optimization problems. Jen-Hao Teng [19] - [20] proposed ant colony system for optimum switch adjustment to improve the service reliability and compared the results from Genetic Algorithm and concluded ACS based optimization finds good results within reasonable computational time and found better one in comparison to GA-based method, since the ACS has the characteristics of positive feedback, distributed computation and the use of a constructive greedy heuristic. Sanjoy Das [21] proposed Ant algorithm for the optimal restoration of distribution feeders during cold load pick up and found better result in comparison to the method based on simulated annealing. Isamu Watanabe [22] proposed Hyper cube ACO for Service restoration in distribution System as the Hyper cube framework for ACO does not depend upon the scale of the problem. A standard ACO algorithm can give different results and more generally may have different behavior, when applied to two isomorphic problems differing only in that one is obtained from the other by multiplying the objective function by a constant value which is an undesirable property and can be removed by implementing ACO algorithm in Hypercube Framework. Lu, Wen and Yang [23] proposed improved ACO for service restoration where to improve the searching efficiency, the behavior of ants are controlled in the feasible set by the spanning tree algorithm and introduced two improved aspects for pheromone update in ACO algorithm. But in all the ACS based techniques mentioned in [19]-[23], the multi-objective nature of the problem is converted to a single objective by the use of weighting factors.

Some times service restoration for whole out of service area is not possible because power flow in the feeders goes beyond their power transfer capacity. In such a case partial restoration plan is achieves minimizing out of service area. The distribution systems are required to operate in radial fashion for proper relay coordination and ease of fault location etc. So the structure of distribution system should remain radial after service restoration also.

In this paper the authors solved the service restoration problem using hybrid Genetic Algorithm-Ant colony Optimization algorithm. During the optimization process of GA-ACO, there is high probability of generation of better solution at every iteration. The string solution is represented by status of switches. In this work, ants search the best string of binary bits on the basis of ranking of objectives. Due to ranking of objectives, multiobjective nature of the problem is retained without the use of tunable weighting factors. As a result the proposed methodology is generalized enough to be applicable to any power distribution network. The applicability of proposed methodology has been demonstrated through detailed simulation studies on four different distribution test systems. The paper is organized as follows. In section II, the detailed mathematical description of the service restoration problem is described in detailed. In section III, the salient features of the GA, ACO and hybrid GA-ACO algorithms are discussed. In section IV, the application of hybrid GA-ACO is described in detail and the main results of this work are discussed in section V. Finally section VI presents main conclusions of this paper.

\section{PROBLEM FORMULATION}

In this paper, the service restoration problem has been formulated as a multi-objective, multi-constrained combinatorial optimization problem. The various formulations for objective functions and constraints developed in this work are described as follows:

\subsection{Objective Functions:}

\section{1) Minimization of Out of Service Area:}

$$
\operatorname{Min} f_{1}(\bar{X})=\sum_{i=1}^{b 1} L_{i}-\sum_{i \in B} L_{i}
$$

$\bar{X}$ is switch state vector of network under
consideration for $\begin{gathered}\text { service } \\ \text { restoration, }\end{gathered}$
$\bar{X}=\left[S W_{1}, S W_{2}, \ldots \ldots \ldots \ldots . . . . .5 W_{N_{S}}\right]$

$$
S W_{j}=\text { Status of } j^{\text {th }} \text { switch. A closed switch is }
$$
represented by 1 and an open switch is represented by 0 .

$N_{S}=$ Total number of switches in the network.

$b 1=$ No. of energized buses in the network before fault. $L_{i}=$ load on $i^{\text {th }}$ bus.

\section{B : Set of energized buses in the restored network.}

In eqn. (1), it is assumed that in a ' $n$ ' bus power system, the buses are numbered from 1 to $n$ and in the prefault case, all the buses in the network are energized. Therefore ' $b 1$ ' is equal to ' $n$ '. However, in the post fault scenario, all the buses would not be necessarily energized. Hence, 'B' would contain only the energized buses. For example, in a 5 bus system, b1 $=5$ and if, in the post-fault case, bus 3 can not be energized, then $B=(1,2,4,5)$.

\section{2) Minimization of number of manually controlled switch operation:}

$$
\min F_{2}(\bar{X})=\sum_{j=1}^{N_{m}}\left|S W M_{j}-S W M R_{j}\right|
$$

Where, $N_{m}$ is number of manually controlled switches.

$$
\begin{aligned}
& S W M_{j}=\text { Status of } j^{\text {th }} \text { manually controlled switch in } \\
& \text { network just after fault. }
\end{aligned}
$$


$S W M R_{j}=$ Status of $j^{\text {th }}$ manually controlled switch in the restored network.

\section{3) Minimization of number of remotely controlled switch operation:}

$$
\min F_{3}(\bar{X})=\sum_{j=1}^{N_{a}}\left|S W A_{j}-S W A R_{j}\right|
$$

Where, $N_{a}$ is number of remotely controlled switches.

$S W A_{j}=$ Status of $j^{\text {th }}$ remotely controlled switch in network just after fault.

$S W A R_{j}=$ Status of $j^{\text {th }}$ remotely controlled switch in the restored network.

\section{4) Minimize the losses:}

$\min F_{4}(\bar{X})=$ Power loss in the restored network which can be calculated with help of load flow.

\subsection{Constraints:}

1) Radial network structure should be maintained.

2) Bus voltage limits should not be violated.

$$
\begin{aligned}
& V_{\text {min }}<V_{j}<V_{\text {max }} \\
& V_{\text {min }}=\text { Minimum acceptable bus voltage. } \\
& V_{j}=\text { Voltage at } j^{\text {th }} \text { bus. } \\
& V_{\text {max }}=\text { Maximum acceptable bus voltage. }
\end{aligned}
$$

3) Feeder line current limits should not be violated.

$$
I_{\min }<I_{j}<I_{\max }
$$

$I_{\text {min }}=$ minimum acceptable line current.

$$
\begin{aligned}
& I_{j}=\text { Current in } j^{\text {th }} \text { line. } \\
& I_{\text {max }}=\text { maximum acceptable line current. }
\end{aligned}
$$

4) Higher priority customers should always be supplied.

In this paper, solution is based on ranking of objectives. As the customer's satisfaction is mostly affected by availability of supply, the first objective function (out of service area) has been kept at the first preference. Moreover to achieve restoration plan in short time should be minimum. Now generally the time taken for operating the manually controlled switch is significantly higher (1200-1500 seconds) in comparison to remotely controlled switches (50-60 seconds). Therefore, between any two solutions, the solution which require fewer manual switch operations would require lesser time to achieve service restoration task compared to other solution. As a result the objective function of minimization of number of manually controlled switch operation has been kept at second preference and that of minimization of remotely controlled switch operations has been kept at the third preference. Finally, the objective function of minimization of losses has been kept at the fourth preference.

\section{METHODOLOGY}

This paper presents hybrid methodology based on Genetic algorithm and Ant Colony Optimization for service restoration problem. Both GA and ACO are population based search algorithm and are sufficiently complex to provide powerful adaptive search approaches and hybridization of GA and ACO speeds up the search performance. The basics of $\mathrm{GA}$ and $\mathrm{ACO}$ are described as follows:

\subsection{Genetic Algorithm (GA)}

GA[31-34] is a general purpose search technique for various optimization problems. It uses a population of solutions, from which, using recombination and selection strategies, better and better solutions are generated.GA can handle any kind of objective functions and constraints without any complex mathematical requirement about the optimization problem Genetic algorithm starts with a set of randomly selected chromosomes as the initial population representing a set of possible solutions. Genes represent variables of the problem and the chromosomes are evaluated according to their fitness function using some measures of profit or utility to optimize. Crossover and mutation are two genetic operators which alter the composition genes of the chromosomes and creates new chromosomes called offsprings. The selection operator is an artificial version of natural selection among the generated offsprings based on Darwinian principle of survival of the fittest, to create populations from generation to generation, and chromosomes with better fitness values having higher probabilities are selected in the next generation. GA converges to the best solution after several such consecutive generations called iteration.

\subsection{Ant Colony Optimization (ACO)}

An Ant Colony Optimization [26]-[30] is a random stochastic population based heuristic algorithm on agents that simulate the natural behavior of ants developing mechanisms of cooperation and learning which enables the exploration of the positive feedback between agents as a search mechanism. An important and interesting behavior of ant colonies is their foraging behavior and, in particular, how ants can find shortest paths between food sources and their nest. While walking from food sources to the nest and vice versa, ants deposit on the ground a chemical substance called pheromone, forming in this way a pheromone trail.

\subsubsection{ACO-implementation for optimization problem}

The Fig.1 illustrates the general ACO algorithm derived from the behavior of real ants. The ACO algorithm manages the scheduling of three activities [26]-[30]. The first step consist the initialization of pheromone trail. In the second iteration step, each ant constructs the complete solution to the problem according to probabilistic state transition rule. The state transition rule depends mainly on the state of the pheromone. The third step updates quantity of the pheromone; a pheromone updating rule is applied in two phases. The first is an evaporation phase where a fraction of pheromone evaporates, and then there is a reinforcement phase increasing the amount of ACO. 


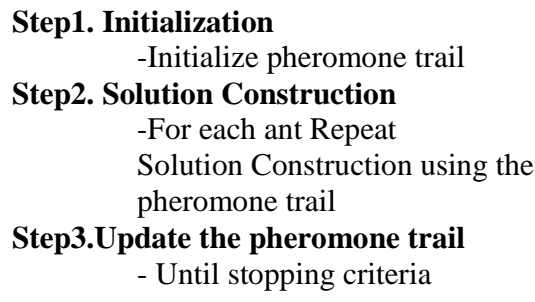

\section{Fig.1 Basic Steps of ACO}

\subsection{Hybrid GA-ACO}

Hybridization of GA and ACO [35-36] relies on the basic concept to overcome its own defects by taking advantage of merits and tributes of two algorithms. GA is capable of extensive global searching in a simple process, applying iteration based on probability and is characterized in randomness and expandability but does not take advantage of positive feedback mechanism as in ACO. Hence solution based on conventional GA require excessive iteration consuming more time and also resulting in low rate of accurate solution. In the hybrid algorithm pheromone in ACO will direct the genetic selection and the results of GA will generate better and better search space using positive feedback mechanism, fully taking advantage of parallelism. Efficiency and other features of ACO allow the two with complementary advantages so as to improve the solution accuracy and efficiency.

The main steps of the proposed hybrid GA-ACO algorithm are discussed below

(i) Generation of search space- In this step, a representation structure of search space for ants is developed which is suitable for ants to search for solution of the problem. Solutions can be represented as a string of binary bits which indicates installation status of switches in the distribution system. The initial search space is generated randomly. The artificial ants search the best string from search space. After first iteration, to generate new search space for ants, GA operators are used. It is similar to generation of offspring population by the single-point crossover method. Moreover, the mutation operator is applied randomly in any string.

(ii) ACO initialization - In the beginning of ACO algorithm, the pheromone values of edges in search space are all initialized to a constant value $\tau_{0}>0$. This initialization causes ants to choose their paths randomly and therefore, search the solution space more effectively. Initialize the other parameters, heuristic parameter $(\beta)$, pheromone parameter $(\alpha)$, evaporation parameter $(\rho)$ for local updating rule and evaporation factor $(\mu)$ for global updating rule.

(iii) Ant Dispatch - In this step, the ants are dispatched for newly generated search space and solutions are constructed based on the level of pheromone on edges. Each ant will start its tour from its home colony and choose one of the states in the next stage to move according to the following transition probability

$$
p_{i j}^{k}(t)=\left\{\begin{array}{cl}
\frac{\left[\tau_{i j}(t)\right]^{\alpha} \cdot\left[n_{i j}\right]^{\beta}}{\sum k \in \text { allowed }_{k}\left[T_{i k}(t)\right]^{\alpha} \cdot\left[n_{i k}\right]^{\beta}} & \text { if } j \in \text { allowed }_{k} \\
0 & \text { otherwise }
\end{array}\right.
$$

Where $\tau_{\mathrm{ij}}(\mathrm{t})$ is the total pheromone deposited on edge $\mathrm{i}, \mathrm{j}$ at iteration ' $\mathrm{t}$ '

and $\alpha, \beta$ are control parameters that control the relative importance of trail versus visibility.

(iv) Quality function assessment on the basis of ranking of objectives- In this step the quality of tours generated by ants is assessed based on the corresponding quality function. For each string of search space, first objective ranked first is evaluated. If two or more solutions have the same value of objective function of first priority, then objective of second priority is evaluated and the process is continued. In any stage if only one solution is there then it is considered the best quality solution and only this solution is allowed to deposit pheromone finally.

(v) Pheromone Update-The aim of the pheromone value update rule is to increase the pheromone values on solution components that have been found in high quality solutions. When a particular ant completes the tour updates pheromone locally at the end of the tour. At the end of each iteration only the best ant is allowed for global update. Also from the practical point of view, pheromone evaporation is needed to avoid too rapid convergence of the algorithm towards a sub optimal solution. It implements a useful form of forgetting favoring the exploration of new areas in the search space. When all ants complete their tour (an iteration), this rule is applied to the states (switches) belonging to the best solution. The rule provides a great amount of pheromone to best solution and is given by

$$
\tau_{i j}(t+1)=(1-\mu) \tau_{i j}(t)+\mu \sum_{k=1}^{m} \Delta \tau_{i j}^{k}(t)
$$

$$
\Delta T_{i j}^{k}=\left\{\begin{array}{cc}
\frac{1}{F_{k}} & \text { if the kth ant uses edge }(i, j) \text { in its tour } \\
0 & \text { (between time } t \text { and } t+n)
\end{array}\right.
$$

Where

$\Delta \mathrm{T}_{\mathrm{ij}} \mathrm{k}^{\mathrm{k}}$ is the change in the pheromone

$\mu$ is the evaporation factor

$\mathrm{F}_{\mathrm{k}}$ is the quality function assessed in equation

$\mathrm{m}$ is the number of ants

The coefficient $\mu$ must be set to a value $<1$ to avoid unlimited accumulation of trail. In order to satisfy the constraint that an ant visits all the n different towns, we associate with each ant a data structure called the tabu list that saves the possible string already visited up to time $\mathrm{t}$ and forbids the ant to visit them again before $\mathrm{n}$ iterations (a tour) have been completed. When a tour is completed, the tabu list is used to compute the ant's current solution (i.e., the distance of the path followed by the ant). The tabu list is then emptied and the ant is free again to choose. We define tabu $\mathrm{k}_{\mathrm{k}}$ the dynamically growing vector which contains the tabu list, of the $\mathrm{k}_{\mathrm{th}}$ ant, $t^{a b u} u_{k}$ the set obtained from the elements of tabu $u_{k}$, and $\operatorname{tabu}_{\mathrm{k}}(\mathrm{s})$ the $\mathrm{s}_{\mathrm{th}}$ element of the list (i.e., the $\mathrm{s}_{\mathrm{th}}$ town visited by the $\mathrm{k}_{\mathrm{th}}$ ant in the current tour). The pheromone update 
information is used for Genetic operators to generate new search space based on positive feedback from pheromone.

(vi) Convergence determination-Steps 3 to 5 continue until the iteration counter reaches the predefined maximum number. The best solution in terms of string selected among all iterations implies the optimum solution4.

\section{IMPLEMENTATION OF HYBRID GA-ACO}

In this work, before application of ACO for solving service restoration problem, the original distribution network is mapped to a graph involving nodes and branches. As for example distribution network of ten switch system shown in Fig. 2 is mapped into graph in Fig.3. The nodes of the graph represent the zones of the original distribution system. A zone is the partial network of the distribution system having no switch. The dark lines of the graph represent 'ON' switches while the hashed lines represent 'OFF' switches. Inside any node, the structure is radial and all the relevant network data such as feeder and load data etc are known from the given distribution network. As a result the structure of graph represents the structure of distribution network, either radial or mesh. Thus, the configuration of the original network is completely described by the status of the switches. Now, various issues of implementation of ACO in this work will be discussed.

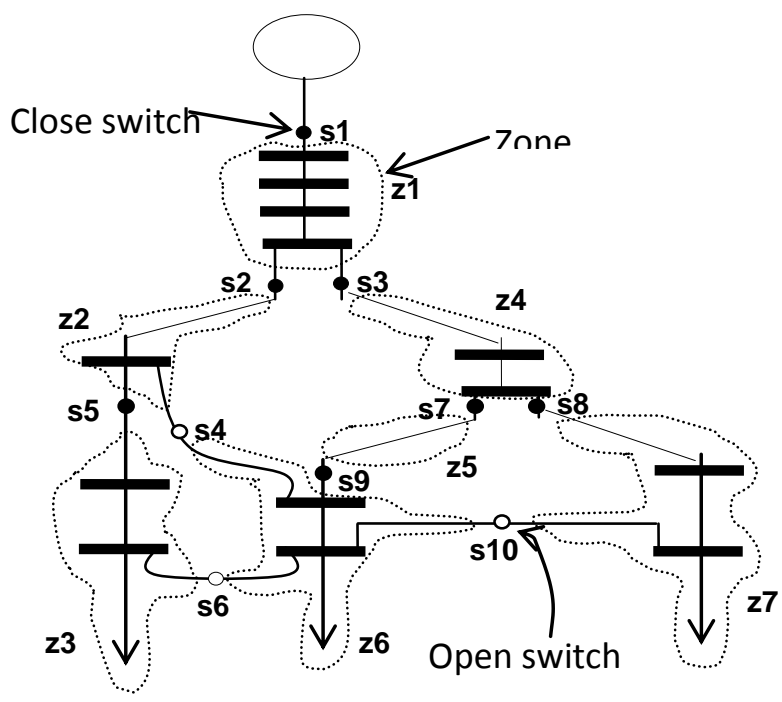

Fig.2 Sample ten- switch System

\section{A. String Representation}

The entire switches in a particular distribution network are represented in terms of string of binary bits. The status of switches such as 'closed' and 'open' are shown ' 1 ' and ' 0 ' respectively. The length of the string (i.e. number of bits in string) is equal to number of switches in the system. For instance, in the network of Fig. 3 switches $S_{1}, S_{2}, S_{3}, S_{5}, S_{7}, S_{8}$ and $\mathrm{S}_{9}$ are closed and rest are open. Therefore the corresponding string for the network configuration is given as $\mathrm{S}=\left[\begin{array}{llllllllll}1 & 1 & 1 & 0 & 1 & 0 & 1 & 1 & 1 & 0\end{array}\right]$, where the indices of the string represent the switch number.

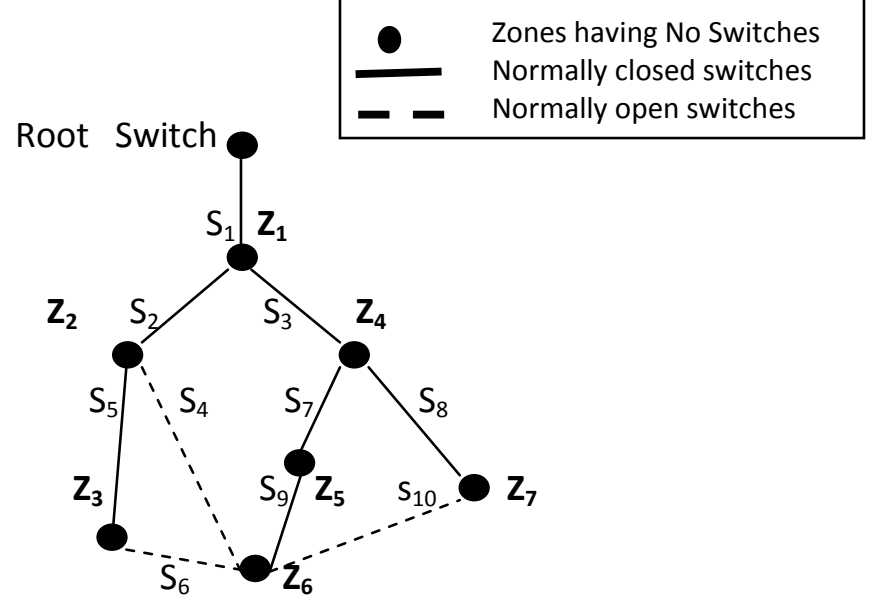

Fig.3. Network Graph of ten-switch system

\section{B. Generation of initial string as search space of Ants}

For execution of ACO algorithm ants require a search space. Search space for ants is provided in form of strings of binary bits. Generally the initial search space is generated randomly. Each string of binary bits is a city for ant to visit and the distance between cities are the value of objective functions ranked from first to fourth for each string. This is the simplest method where no knowledge about the network is required. The generation of the initial strings as search space for ants is restricted to meet the following requirements.

(i) Root switches are always connected i.e. kept always equal to " 1 " in all the possible binary strings of the expected newly reconfigured network as the opening the root switch will isolate the entire bus system. Root switch is one nearest to the substation connecting the entire bus system.

(ii) The faulted zone is always isolated by making the element in all strings, corresponding to switches around the faulted zone, " 0 ".

(iii) By running load flow calculation all the constraints and conditions mentioned in (i) and (ii) are checked and only those possible strings are allowed for search space which do not violates the constraints and above mentioned conditions.

\section{Radiality Checking}

To check the radiality of the system, a breadth-first-traversal of the network starts from the root switch and travels downwards of the distribution network proposed by Y kumar et al [18]. The root switch from where the traversal starts is called the first level switch. If any switch under consideration is closed, the reachable zones connected to downstream side and hence, is marked "visited". On the other hand, the unreachable switches connected at the downstream side are marked "unvisited". After consideration of all first level switches, zones marked "visited" are entered in a list " $L$ ". The switches connected to "visited" zone downstream side are called second level switches. The same procedure just mentioned for first level switches is repeated and list " $\mathrm{L}$ " is updated. The switches connected to zones recently admitted in list " $L$ " are third level switches and the procedure is repeated again and again till there is no switch left in the next level. The earlier mentioned procedure is illustrated as follows for the network shown in Fig.2, in which switch $S_{1}$ is root switch. First level switch- $S_{1}$ 
Zones "visited" connected with first level switch- $Z_{1}$ Second level switches- $\mathrm{S}_{2}, \mathrm{~S}_{3}$

Zones "visited" connected with second level switch- $\mathrm{Z}_{2}, \mathrm{Z}_{4}$

Third level switches- $\mathrm{S}_{4}, \mathrm{~S}_{5}, \mathrm{~S}_{7}, \mathrm{~S}_{8}$

Zones "visited" connected with third level switch- $\mathrm{Z}_{3}, \mathrm{Z}_{5}, \mathrm{Z}_{7}$

Fourth level switches- $\mathrm{S}_{6}, \mathrm{~S}_{9}, \mathrm{~S}_{10}$

Zones "visited" connected with third level switch- $Z_{6}$

Fifth level switches-nil, all zones are "visited"

The presence of loop is detected if any of the zones is "visited" more than once during the traversal. The switch currently under considered is made 'OFF' to maintain the radiality. After the completion of network traversal all the "visited" zones are put list "EZ" called "existing zones". The "existing zones" are actually energized zones.

\section{String evaluation based on ranking}

After checking the radiality, all strings give a radial configuration and their corresponding existing zones are recorded through which existing buses and lines are found. With the knowledge of the existing buses all the objective functions are calculated for each string of search space. AC load flow study is conducted to calculate system losses, bus voltage and line current violations. The solutions having minimum out of service area will be considered string of better quality. If two or more strings have the same value of objective function of first priority, then objective of second priority is evaluated and the process is continued. In any stage only one solution is left, then it is considered the best quality solution. Ants search for the best quality solution from the existing strings of search space and deposit pheromone for best string assessed earlier.

\section{E. Partial Restoration}

During the restoration process, if no such string in search space is generated which can restore entire out of service area without violating any constraint, the string, which can restore maximum portion of out of service area without violating any constraint, is selected and kept in better front.

\section{F. Generation of next search space by string operation}

To generate new search space for ants GA operators are used. It is similar to generation of offspring population by the single-point crossover method. Moreover, the mutation operator is applied randomly in any string. After the generation of new search space, radiality of each string is evaluated. If any of the string is found non radial, it is made radial following the procedure in part $\mathrm{C}$ of this section.

\section{G. Convergence}

Convergence of ACO algorithm is determined as mentioned in step- 6 of section III. If two or more strings have the same value of objective functions ranked first to fourth, all solutions are declared equally good.

\section{H. Steps of Algorithm for Service Restoration}

(I) The information available to the ACO algorithm are (a) system data; (b) prefault configuration and (c) post fault configuration.

(II) Generate initial search space $S_{0}$ for ants following the procedure described in part $\mathrm{B}$ of this section.
(III) Check the radiality of the solutions in search space and modify them, if necessary, following the procedure described in part $\mathrm{C}$ of this section.

(IV) Initialize the parameters for ACO search

(a) No. of ants

(b) No. of iterations

(c) Initial pheromone values of each string $\left(\tau_{0}>0\right)$ as mentioned in step 2 of section III.

(d) Pheromone parameter $(\alpha)$

(e) Heuristic parameter $(\beta)$

(f) Evaporation factor for local $(\rho)$ and global updating rule $(\mu)$

(V) The ants are dispatched and solutions are constructed based on the level of pheromone on edges i.e. string of binary bits as mentioned in step (iii) of Section 3. The number of ants will be less than or equal to the number of strings generated in search space.

(VI) In this step the quality of tours generated by ants is assessed based on the corresponding quality function as mentioned in part $\mathrm{D}$ of this section

(VII) In this step, pheromone is updated locally and globally as described in step 5 of section 3 .

(VIII) Generate new search space $\mathrm{S}_{\mathrm{t}+1}$ as mentioned in part $F$ of this section and in all strings of new search space, the faulted zone is isolated and the root switch is always made "closed" as described in part B of this section.

(IX) Check the radiality of the strings in new search space $S_{t+1}$ and modify them, if necessary as mentioned in part $\mathrm{C}$ of this section.

Steps 5 to 8 continue until the iteration counter reaches the predefined maximum number. The best string selected among all iterations implies the optimum solution.

\section{RESULTS AND DISCUSSION}

The effectiveness of the Ant Colony System algorithm for service restoration has been studied on four different distribution systems. The details of these systems are given in Table I.

As already mentioned in the previous section, in this work, the Hybrid GA-ACO technique with reduced run time complexity has been implemented. The performance of proposed algorithm has also been compared with that of the Nondominated Sorting of Genetic Algorithm NSGA-II developed by Deb [34] conventional GA and existing method of service restoration Luan et al [13]

Here the results corresponding to 10 bus, 14 switches system (system-II) are only illustrated. Fig. 2 shows the schematic diagram of the 10-bus, 14-switch system. In this system, it has been assumed that the fault has taken place at point $\mathrm{A}$ (also indicated in Fig.4) and due to this fault, the switch $\mathrm{S}_{4}$ trips for isolating the fault. As a result, the area shown inside the closed curve is left without electric power. The supply to this "out-ofservice" area can be restored either by closing switch $\mathrm{S}_{14}$ (let it be called option A) or by closing switch $\mathrm{S}_{12}$ (let it be called option B). Now, switch $S_{12}$ is an automatic, remote controlled switch with a typical operating time of 50 seconds whereas, switch $\mathrm{S}_{14}$ is a manually controlled switch with operating time typically in the range of 1200-1500 seconds. It is to be noted that the operating time of a manually controlled switch depends on its distance from the nearest manned substation (from which an operator has to travel to operate the switch). Now, by both these options, the entire "out-of-service" area can be supplied. Therefore, from the considerations of the objective function kept at first preference, both these options 
are equally preferable. However, as option B takes considerably less time as compared to option A to accomplish the service restoration task, this option is chosen.

Table I: Details of different Test Systems

\begin{tabular}{|c|c|c|c|c|c|}
\hline $\begin{array}{c}\text { SL. } \\
\text { No. }\end{array}$ & $\begin{array}{c}\text { Descripti } \\
\text { on }\end{array}$ & $\begin{array}{c}\text { No. of } \\
\text { Buses }\end{array}$ & $\begin{array}{c}\text { No. of } \\
\text { Switches }\end{array}$ & $\begin{array}{l}\text { Systems } \\
\text { nominal } \\
\text { voltage } \\
\text { (KV) }\end{array}$ & $\begin{array}{l}\text { No. of } \\
\text { load } \\
\text { points }\end{array}$ \\
\hline 1 & System-1 & 13 & 10 & 11 & 12 \\
\hline 2 & System-2 & 10 & 14 & 13.8 & 19 \\
\hline 3 & System-3 & 33 & 37 & 12.66 & 31 \\
\hline 4 & System-4 & 173 & 75 & 33 & 88 \\
\hline
\end{tabular}

Table II: Various single fault locations

\begin{tabular}{|c|c|c|c|c|}
\hline System & System-1 & System-2 & System-3 & System-4 \\
\hline $\begin{array}{c}\text { Fault } \\
\text { location }\end{array}$ & $\begin{array}{c}\mathrm{z} 4 \\
\text { (between } \\
\text { bus } \\
4 \text { and 8) }\end{array}$ & $\begin{array}{c}\text { z6 } \\
\text { (between } \\
\text { bus } \\
1 \text { and 4) }\end{array}$ & $\begin{array}{c}\mathrm{z} 4 \\
\text { (between } \\
\text { bus } \\
3 \text { and 4) }\end{array}$ & $\begin{array}{c}\mathrm{z} 52 \\
\text { (between } \\
\text { bus } \\
104 \text { and } \\
105 \text { ) }\end{array}$ \\
\hline $\begin{array}{l}\text { Priority } \\
\text { customer }\end{array}$ & $\mathrm{z6}$ & $\mathrm{z} 3$ & $\mathrm{z} 21$ & $\mathrm{z} 62$ \\
\hline $\begin{array}{c}\text { Switch } \\
\text { tripped } \\
\text { due to } \\
\text { fault }\end{array}$ & 3 & 4 & 9 & 52 \\
\hline $\begin{array}{l}\text { Remotely } \\
\text { controlled } \\
\text { switches }\end{array}$ & $1,4,7$ & $1,2,3,7,12$ & $\begin{array}{c}2,3,6,8,11,2 \\
4,34\end{array}$ & $\begin{array}{c}7,13,20,32, \\
42,49, \\
52,63,71,74\end{array}$ \\
\hline
\end{tabular}

Similar kind of studies for different single and multiple faults shown in Table II and VI have also been carried out for all the other systems and the results are shown in Table IV and VII.

Various GA-ACO algorithm parameters are shown in Table III.

Table III: GA-ACO parameters in test cases

\begin{tabular}{|l|l|}
\hline \multicolumn{1}{|c|}{ Parameters } & Value \\
\hline Number of Ants & 10 \\
\hline Pheromone evaporation rate & 0.9 \\
\hline Maximum no of iterations & 100 \\
\hline Initial Pheromone on strings & 0.1 \\
\hline Size of search space & 10 \\
\hline Cross over rate (Single Point) & 0.8 \\
\hline Mutation Rate per gene(bit) & 0.05 \\
\hline
\end{tabular}

In the result tables, the entries corresponding to the "out-ofservice" area has been given in terms of the total amount of load (in KW) left unsupplied. For example, from Table IV, it can be concluded that $600 \mathrm{KW}$ of total load is always left unsupplied in system-1, irrespective of whichever solution methodology is used. Actually, in system-1, the load in the faulted zone is $600 \mathrm{KW}$ and as this zone is isolated following a fault, this load cannot be restored by any technique. Similarly, the faulted zones in system- 2 and system- 3 contain $100 \mathrm{KW}$ and $120 \mathrm{KW}$ of load respectively and as a result, these loads can also not be restored by any of the methods. System-4, however, does not contain any load in the faulted zone considered by using methods GA-ACO and NSGA-II while by convention GA load of $3134 \mathrm{KW}$ remains unsupplied. Moreover due to generation of lot of infeasible solution on the basis of probability in conventional GA, run time required for the algorithm is very high in comparison to proposed hybrid GA-ACO technique. NSGA-II developed by Deb [34] also require more time than hybrid GA-ACO. Conventional GA requires more manual switch operations than NSGA-II and hybrid GA-ACO. All the three methods are able to restore Priority customers. Based on results in Table IV, hybrid GA-ACO is found to be the best technique among three.

Table IV: Single fault full service restoration

\begin{tabular}{|c|c|c|c|c|c|}
\hline \multicolumn{2}{|c|}{ System } & System- & System- & System- & System- \\
\hline \multirow{3}{*}{ 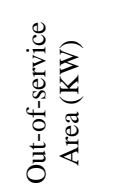 } & GA-ACO & 600 & 100 & 120 & 0.0 \\
\hline & NSGA-II & 600 & 100 & 120 & 0.0 \\
\hline & GA & 600 & 100 & 120 & 3134.0 \\
\hline \multirow{3}{*}{ 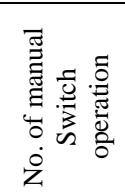 } & GA-ACO & 2 & 1 & 1 & 0 \\
\hline & NSGA-II & 2 & 1 & 1 & 0 \\
\hline & GA & 3 & 2 & 2 & 2 \\
\hline \multirow{3}{*}{ 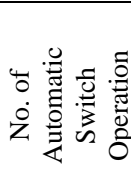 } & GA-ACO & 2 & 1 & 1 & 2 \\
\hline & NSGA-II & 2 & 1 & 1 & 2 \\
\hline & GA & 1 & 0 & 0 & 0 \\
\hline \multirow{3}{*}{ 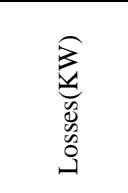 } & GA-ACO & 104.50 & 582.40 & 210.00 & 15181.3 \\
\hline & NSGA-II & 104.50 & 582.40 & 210.00 & 15181.3 \\
\hline & GA & 106.86 & 579.0 & 216.0 & 14052.4 \\
\hline \multirow{3}{*}{ 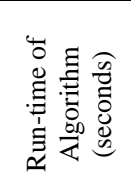 } & GA-ACO & 16.792 & 21.465 & 49.673 & 103.253 \\
\hline & NSGA-II & 22.538 & 30.121 & 75.812 & 168.800 \\
\hline & GA & 43.807 & 64.910 & 195.311 & 435.400 \\
\hline \multirow{3}{*}{ 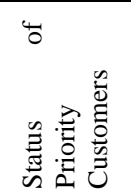 } & GA-ACO & Yes & Yes & Yes & Yes \\
\hline & NSGA-II & Yes & Yes & Yes & Yes \\
\hline & GA & Yes & Yes & Yes & Yes \\
\hline
\end{tabular}

To evaluate the performance of the proposed algorithm for multiple faults in a distribution system, several studies involving simultaneous multiple faults have been carried out. Table V represents the description of multiple faults with location of bus and the tripped switches following fault to isolate faulted zone.

Table VI represents the results for four distribution systems due to multiple faults. In case of multiple faults number of switch operations will be more than single fault cases.

Results in table VI reflects that GA performs poorest among the three proposing more out of service area, no of manual switch operations and losses in more run time due to lot of iterations. Though NSGA-II is the improved version of conventional GA but it also require more run time than hybrid method of GA-ACO.

In the present work only those solutions have been considered which satisfies all the four constraints. If any of the constraint is violated by any solution is discarded in the final solution. Moreover, it has been assumed that the substation has enough capacity to supply the entire distribution network. It is 
therefore not needed to cut off any noncritical load in order to supply the priority customers.

Table V: Various multiple fault locations

\begin{tabular}{|c|c|c|c|c|}
\hline System & System-1 & System-2 & System-3 & System-4 \\
\hline $\begin{array}{l}\text { Fault } \\
\text { location } \\
1^{\text {st }}\end{array}$ & $\begin{array}{c}\mathrm{z3} \\
\text { (between } \\
\text { bus } 6 \text { and } \\
7 \text { ) } \\
\end{array}$ & $\begin{array}{c}\mathrm{z} 2 \\
\text { (between } \\
\text { bus } 1 \text { and } \\
\text { 2) } \\
\end{array}$ & $\begin{array}{c}\mathrm{z} 4 \\
\text { (between } \\
\text { bus } 3 \text { and } \\
4 \text { ) } \\
\end{array}$ & $\begin{array}{c}\mathrm{z} 52 \\
\text { (between } \\
\text { bus } 104 \\
\text { and 105) }\end{array}$ \\
\hline $\begin{array}{l}\text { Fault } \\
\text { location } \\
2^{\text {nd }}\end{array}$ & $\begin{array}{c}\mathrm{z} 4 \\
\text { (between } \\
\text { bus } 8 \text { and } \\
9 \text { ) } \\
\end{array}$ & $\begin{array}{c}\text { z6 } \\
\text { (between } \\
\text { bus 1and 4) }\end{array}$ & $\begin{array}{c}\mathrm{z} 15 \\
\text { (between } \\
\text { bus } 15 \text { and } \\
16 \text { ) } \\
\end{array}$ & $\begin{array}{c}\mathrm{z} 18 \\
\text { (between } \\
\text { bus } 40 \text { and } \\
41 \text { ) } \\
\end{array}$ \\
\hline $\begin{array}{l}\text { Fault } \\
\text { location } \\
3^{\text {rd }}\end{array}$ & - & $\begin{array}{c}\text { z8 } \\
\text { (between } \\
\text { bus 3and 7) }\end{array}$ & $\begin{array}{c}\mathrm{z} 9 \\
\text { (between } \\
\text { bus } 9 \text { and } \\
10 \text { ) }\end{array}$ & $\begin{array}{c}\mathrm{z} 47 \\
\text { (between } \\
\text { bus } 90 \text { and } \\
92 \text { ) }\end{array}$ \\
\hline $\begin{array}{l}\text { Fault } \\
\text { location } \\
4^{\text {th }}\end{array}$ & - & - & $\begin{array}{c}\mathrm{z} 26 \\
\text { (between } \\
\text { bus } 26 \text { and } \\
27 \text { ) } \\
\end{array}$ & $\begin{array}{c}\mathrm{z} 62 \\
\text { (between } \\
\text { bus } 161 \\
\text { and } 163 \text { ) } \\
\end{array}$ \\
\hline $\begin{array}{c}\text { Tripped } \\
\text { switches }\end{array}$ & $\begin{array}{c}5 \& 3 \\
\text { respectively }\end{array}$ & $\begin{array}{c}2,4 \& 11 \\
\text { respectively }\end{array}$ & $\begin{array}{c}9,21,15 \& \\
25 \\
\text { respectively }\end{array}$ & $\begin{array}{c}52,2,46 \\
\& 60 \\
\text { respectively }\end{array}$ \\
\hline
\end{tabular}

Table VI: Multiple fault full service restoration

\begin{tabular}{|c|c|c|c|c|c|}
\hline \multicolumn{2}{|l|}{ System } & $\begin{array}{l}\text { System- } \\
1\end{array}$ & $\begin{array}{l}\text { System- } \\
2\end{array}$ & $\begin{array}{l}\text { System- } \\
3\end{array}$ & $\begin{array}{l}\text { System- } \\
4\end{array}$ \\
\hline \multirow{3}{*}{ 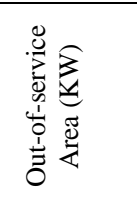 } & $\begin{array}{l}\text { GA- } \\
\text { ACO }\end{array}$ & 853.0 & 2000 & 300 & 8642.0 \\
\hline & $\begin{array}{l}\text { NSGA- } \\
\text { II }\end{array}$ & 853.0 & 2000 & 300 & 8642.0 \\
\hline & GA & 853.0 & 2000 & 300 & 8642.0 \\
\hline \multirow{3}{*}{ 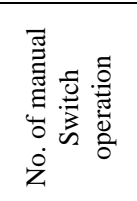 } & $\begin{array}{l}\text { GA- } \\
\text { ACO }\end{array}$ & 4 & 3 & 5 & 2 \\
\hline & $\begin{array}{l}\text { NSGA- } \\
\text { II }\end{array}$ & 4 & 3 & 5 & 2 \\
\hline & GA & 4 & 4 & 6 & 2 \\
\hline \multirow{3}{*}{ 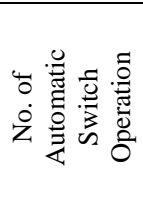 } & $\begin{array}{l}\text { GA- } \\
\text { ACO }\end{array}$ & 0 & 1 & 3 & 2 \\
\hline & $\begin{array}{l}\text { NSGA- } \\
\text { II }\end{array}$ & 0 & 1 & 3 & 2 \\
\hline & GA & 0 & 1 & 2 & 2 \\
\hline \multirow{3}{*}{ 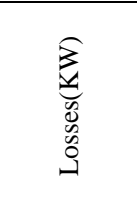 } & $\begin{array}{l}\text { GA- } \\
\text { ACO }\end{array}$ & 95.3 & 187.3 & 148.11 & 12337.2 \\
\hline & $\begin{array}{l}\text { NSGA- } \\
\text { II }\end{array}$ & 95.3 & 187.3 & 148.11 & 12337.2 \\
\hline & GA & 96.1 & 198.3 & 157.0 & 12665.1 \\
\hline \multirow{3}{*}{ 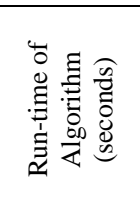 } & $\begin{array}{l}\text { GA- } \\
\text { ACO }\end{array}$ & 11.572 & 17.352 & 41.252 & 89.538 \\
\hline & $\begin{array}{l}\text { NSGA- } \\
\text { II }\end{array}$ & 19.673 & 25.874 & 69.194 & 160.828 \\
\hline & GA & 61.882 & 60.598 & 189.352 & 426.982 \\
\hline \multirow{3}{*}{ 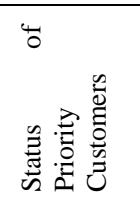 } & $\begin{array}{l}\text { GA- } \\
\text { ACO }\end{array}$ & Yes & Yes & Yes & Yes \\
\hline & $\begin{array}{l}\text { NSGA- } \\
\text { II }\end{array}$ & Yes & Yes & Yes & Yes \\
\hline & GA & Yes & Yes & Yes & Yes \\
\hline
\end{tabular}

\section{CONCLUSION}

In this paper, a hybrid GA-ACO based technique is developed for solving the service restoration problem in the electric power distribution system. In this study, various practical issues of distribution system operation, such as presence of important key customers like hospitals, industries are considered. Moreover manually controlled switches and remotely controlled switches are considered separately as objective function which helps in applying restoration plan practically in short time as the operating time of manually controlled switches are significantly high in order of 1200 1500 seconds in comparison to remotely controlled switches having operating time of 50-60 seconds. The advantage of the proposed hybrid GA-ACO based technique is that it does not require weighting factors as needed in conventional optimization techniques. Moreover the proposed technique overcomes the demerits of GA and ACO both. Demerit of GA to produce infeasible solution is controlled by positive feedback mechanism based on Pheromone of ACO and demerit of ACO to take large convergence time is controlled by controlling the no of ants and size of search space generated by GA. Based on larger number of simulation studies, it has been found that the hybrid GA-ACO based technique performs far better than conventional GA in all respects and significantly better than NSGA-II in respect of run time of algorithm. Number of iterations required to get best solution is also very less in comparison to NSGA-II and GA. It is therefore hybrid GA-ACO based technique is most suitable for real time implementation both in terms of accuracy and speed.

\section{REFERENCES}

[1] Akoi, H. Kuwabara T. Satoh M. Kanezashi, "Outage state optimal load allocation by automatic sectionalizing switches operation in distribution systems," IEEE trans. Power delivery. 1987,vol. 2, no.4, pp. 1177-1185

[2] K.Akoi , H. Kuwabara T. Satoh M. Kanezashi, "Voltage drop constrained restoration of supply by switch operation in distribution system," IEEE trans. Power delivery. 1988 vol. 3, no. 3, pp. 1267-1279.

[3] K. Akoi, H. Kuwabara T. Satoh M. Kanezashi, "A new algorithm for service restoration in distribution systems," IEEE trans. Power delivery. 1989 vol. 4, no. 3, pp.18321839.

[4] C. C. liu S. J. Lee, S.S. Venkata "An expert system operational aid for restoration and loss reduction of distribution systems," IEEE trans.Power syst.1988 vol. 3, no. 2, pp. 619-626

[5] C. E. Lin et al., "A distribution system outage dispatch by data base method with real time revision," IEEE trans. Power Delivery, vol. 4. Jan.1989.

[6] Imamura et al., "An application of fuzzy reasoning for service restoration" (in Japanese) Trans. IEE Jpn., vol. 4, July 1989.

[7] H. Mori et al., Parallel simulated annealing for power system decomposition," IEEE trans. Power system vol. 4, May 1994.

[8] S. Toune, H. Fudo, T. Genji, Y. Fukuyama, Y. Nakanishi, "A reactive tabu search for service restoration in electric power distribution system," IEEE International conference on evolutionary computation," Anchorage Alaska, May 4-11 1998.

[9] H.C.Kuo and Y.Y Hsu, " Distribution system load estimation and service restoration using a fuzzy set approach", IEEE Transactions on Power delivery, Vol-8, No-4, pp-1950-1957, Oct.1993 
[10] S.J.Lee, S.I.Lim, and B.S.Ahn, " Service restoration of primary distribution system based on fuzzy evaluation of multi criteria", IEEE Transactions on Power System, Vol-13, No-3, pp-1156-1163, Aug.1998

[11] Y. Fukuyama and H. D. chaing, "A parallel genetic algorithm for service restoration in electric power systems," in proceeding IEEE FUZZ/FES Conference, Yokohama, Japan, Mar. 1995.

[12] A. Augugliaro, L.Dusonchet, E.R. Sanseverino, "Service restoration in compensated distribution networks using a hybrid genetic algorithm," Electric power syst. Research, 1998, vol. 46, 59-66.

[13] W.P. Luan, M.R.Irving, J.S. Daniel, "Genetic algorithm for supply restoration and optimal load shedding in power system distribution networks," IEE Proc. Gener. Transm. Distrib., 2002, vol. 149, no. 2, pp. 145-15 1.

[14] Y. T. Hsiao and C. Y. Chien, "Enhancement of restoration service in distribution systems using a combination of fuzzy-GA method," IEEE

[15] Yogendra Kumar, Biswarup Das, Jaydev Sharma, Genetic Algorithm for supply restoration in distribution system with priority customers $9^{\text {th }}$ international Conference on Probabilistic Methods applied to power systems , Sweden, June 2006.

[16] R. E. Brown, S. Gupta, R. D. Christie and S. S. Venkata, "A genetic algorithm for reliable distribution system design", International Conference on Intelligent Systems Applications to Power Systems, ISAP '96., pp. 29-33, January 28 - February 2,1996.

[17] S. Chavali, A. Pahwa and S. Das, "A genetic algorithm approach for optimal distribution feeder restoration during cold load pickup", Proceedings of the Congress on Evolutionary Computation, CEC '02, vol. 2, pp. 18161819, May 12-17, 2002.

[18] Y.Kumar, B.Das and J.Sharma, “ Multiobjective, multiconstraint service restoration of electric power distribution system with priority customers", IEEE Transactions on Power delivery, Vol-23, No-1, pp-261270, Jan.2008

[19] Jen-Hao Teng,Yi-Hwa Liu, "Application of the Ant Colony System for Optimum switch adjustment", IEEE Transactions on power Systems,Vol.17,No.1,pp.751756,2002

[20] Jen-Hao Teng,Yi-Hwa Liu, “ A Novel ACS-Based optimum Switch Relocation Method" IEEE Transactions on power systems,Vol.18,No.1,pp.113-120,2003.

[21] Indira Mohanty,Jugal Kalita,Sanjoy Das,Anil Pahwa,Erik Buehler, "Ant Algorithm for the optimal restoration of Distribution feeders during cold load pickup',IEEE Transactions on Power Delivery,pp.132-137,2003.

[22] Isamu Watanabe, "An ACO Algorithm for service Restoration in Power Distribution Systems", IEEE Transactions on Power delivery, pp.2864-2871,2005

[23] Zhigang Lu, Ying wen, Lijun Yang, “An Improved ACO algorithm in Power Distribution Systems" IEEE transactions on Power Delivery,2009

[24] H. Falaghi,M.RHaghifam, and Chanan Singh, "Ant Colony optimization-Based Method for placement of Sectionalizing Switches in Distribution Network Using a
Fuzzy Multiobjective Approach' IEEE transactions on Power Delivery,Vol.24,No.1,pp.268-276,2009

[25] Rajeev Annaluru,Sanjoy Das,anil Pahwa, "Multi-level Ant Colony Algorithm for Optimal Pacement of Capacitors in Distribution systems", IEEE Transactions on Power Delivery,pp.1932-1937,2004

[26] M. Dorigo, L.M.Gambardella, "Ant Colony System:A Cooperative Learning Approach to the Travelling salesman Problem",IEEE Transactionson Evolutionary Computations, Vol,1,pp.53-66,1997.

[27] T.Stutzle, M.Dorigo, "A short convergence proof for a class of ant colony optimization algorithm", IEEE Transactions on Evolutionary Computation, Vol,6,Issue:4, pp.358-365,2002.

[28] M.Dorigo and T.Stutzle, "Ant Colony Optimization”,Cambridge,MA:MIT Press,2004

[29] M.Dorigo, M. Birattari, T. Stutzle “ Ant colony optimization: artificial ants as a computational intelligence technique" IEEE Transactions on Evolutionary Computation, pp.358-365,2006.

[30] Marco Dorigo, Member, IEEE, Vittorio Maniezzo, and Albert Colorni, Ant System: Optimization by a Colony of Cooperating Agents IEEE Transactions on systems, man $\&$ cybernetics-part-b cybernetics, vol 26 , no. 1 , February 1996,29 .

[31] M.Gen, R.Cheng, Genetic algorithm and Engineering Design, John Wiley and sons Inc., 1997

[32] Z.J.Lee, S.F.Su,C.Y.Lee, Efficiently solving generalweapon target assignment problem by genetic algorithms with greedy eugenics, IEEE Trans. System., Man Cyber.Part B 33 (2003) pp 113-121.

[33] J. Miller, W.Potter, R. Gandham, C.Lapena, “ an evaluation of local improvement operators for genetic algorithm, IEEE transaction. System.,man cyber 23(5), $1993,1340-1341$

[34] K.Deb, A.Pratap, S.Agrawal, and T.Meyarivan, “ A fast and elitist multi objective genetic algorithm:NSGAII”,IEEE Tranns.Evol.Comput.,Vol.6, No.2,pp-182197,Apr.2002

\section{AUTHOR'S PROFILE}

Rajneesh Kumar Karn born in 1978 in India. He received the M.Tech degree in Heavy Electrical Equipment from Maulana Azad National Institute of Technology, Bhopal in 2006.He is working towards the Ph.D. degree in Power System from Maulana Azad National Institute of Technology, Bhopal. Presently he is working as Associate Professor in Electrical Engineering Department in Radharaman Engineering College, Bhopal, India. His research interests are in area of optimization technique in Electrical Distribution Systems.

Yogendra Kumar born in 1965. He recieived the M.tech degree in Heavy Electrical Equipment from Maulana Azad College of Technology, Bhopal, India in 1998 and Ph.D. degree in Power System from IIT Roorkee, India in 2006.Presently he is working as Professor in Electrical Engineering Department in Maulana Azad National Institute of Technology, Bhopal, India. His areas of research interests are Distribution automation and Optimization.

Gayatri Agnihotri born in 1947. She received M.Tech in Heavy Electrical Equipment from Maulana Azad College of 
Technology, Bhopal, India in 1974 and Ph.D. in Power system from IIT Delhi, India in 1984. She worked as professor in Electrical Engineering Department and Dean in Maulana Azad National Institute of Technology, Bhopal, India for more than 35 years.Presently, she is working as Director, Radharaman Engineering College, Bhopal. Her areas of interests include FACTS devices, Power System distribution automation and optimization. 